\title{
Utilizing the Blackboard Learning Management System at the University of Ha'il from the Perspective of Faculty Members using Internet Of Things (IOT)
}

\author{
Abdulaziz Ali Alzahrani \\ Associate professor College of Education \\ Ha'il University \\ Hail, KSA \\ alzahrani.aziz@gmail.com \\ Khaled Abu Sheirah \\ Professor at Deanship of Preparatory \\ Ha'il University \\ Hail, KSA \\ dr.khalid13@yahoo.com
}

Received: January 13, 2021. Revised: February 19, 2021. Accepted: February 19, 2021. Published: February 22, 2021.

\begin{abstract}
The study aims to investigate the perceptions of faculty members in the preparatory year at the University of Ha'il concerning the use of the Blackboard learning management system, and to identify the impact of the study variables (gender, discipline, teaching language, and number of training courses) on the responses of the study sample members. A descriptive methodology has been used, as the study was applied to a sample of (123) faculty members, and to collect information, a questionnaire of (32) items was developed. The results of the study showed that the level of using the Blackboard at the University of Ha'il by faculty members was high. It indicated that there were no statistically significant differences due to gender. Moreover, the results revealed that there were no statistically significant differences $(p=0.218)$ in the use of Blackboard based on the number of training courses, and that there were no statistically significant differences $(p=0.390)$ in the use of Blackboard based on academic ranking.
\end{abstract}

Keywords: blackboard, faculty members view, quantitative research, Internet Of Things (IOT) University of Hail.

\section{INTRODUCTION}

I $\mathrm{N}$ light of technological development and the challenges facing faculty members in public and private universities due to the weakness of their technological skills, it has become necessary to train them and develop their technological competencies in accordance with the requirements of the times, in addition to enhancing their active role in achieving international quality standards in education. This will provide university graduates with skills and knowledge that rely on innovation and creativity, as per the requirements of the labor market [1]. Focusing the attention on faculty members and their preparation and rehabilitation is a fundamental pillar that can support vital changes in the educational process. From this perspective, universities have sought to benefit from technical and technological development to serve the educational process, and to provide an attractive and stimulating environment for teaching and learning. Thus, universities have been keen to apply modern and sophisticated e-learning systems in teaching and training. Therefore, many Western and Saudi universities have utilized and benefited from the communication and information technology revolution in their academic programs, in conjunction with technical and technological development. They rely on the use of the internet in general or university education, and have established electronic libraries that provide e-books, electronic periodicals, audio or video clips, as well as other electronic resources, and have also utilized e-learning. In light of this technological advancement, learning management systems (LMS) have emerged. These are considered useful tools for faculty members in the educational process to deliver the requirements of the course, whether it is educational content, tests, or other electronic activities [2].

The University of Ha'il has worked on incorporating the Blackboard learning environment within its educational system to work alongside classroom learning, and to achieve the desired learning objectives as an e-learning system in 2014. It also encouraged faculty members from all disciplines to use it 
alongside classroom education to support their curricula, and rewarded faculty members using the Blackboard with a letter of appreciation provided by the college or deanship. In addition to that, the University of Ha'il takes into account the use of the Blackboard when evaluating faculty members, and provides different facilities, such as training courses, user manuals and technical support.

Blackboard is famous for being a safe and easy-to-use virtual learning environment that manages the educational process, allowing faculty members to provide educational content and lectures through several educational media. They communicate with their students through communication tools without place and time constraints, via computers or smart devices 'Some relevant studies can be found in [3];[4];[5] and.[6]

Blackboard system includes several features and supports several file formats for electronic publishing, in order to enable users to easily save and retrieve course material contents. The Blackboard system also includes platforms for communication and content sharing [7];[8];[9].

These communication platforms include:

- Announcements: Enables faculty members to send students news or announcements.

- Chat: Enables faculty-student and student-student discussions, provided they are present at the same time.

- Discussions: Enables faculty members and students to create a discussion topic with a reply feature that does not require their presence at the same time.

- Mail: This feature enables faculty members and students to send each other mail.

- Content sharing includes:

- Course Content: Enables faculty members to upload articles, assignments, and educational media.

- Calendar: This feature informs students of the exact dates of tests and tasks.

- Assignments: This feature enables students to upload required assignments and submit them to faculty members.

- Media Library: members upload audio or video clips that students can view.

- Assessment: Enables faculty members to raise periodic or final tests for students, and requires that students have an internet connection to take the tests.

\section{THEORETICAL RSSI MODEL}

Many previous studies in the field of using the Blackboard system were conducted within Arab and foreign environments. Shipman's study aimed to identify faculty member trends in the integration of technology for undergraduate lectures at the University of South Texas in the United States of America. The study concluded that all interviewed faculty members agreed that Blackboard had a positive impact on students' learning and educational progress. Blackboard is considered to be a teaching assistant that meets the educational needs of students, representing a synchronous and asynchronous link between students and faculty members. It's also an effective tool for following up with the educational progress of students through their results on tests and assignments throughout the year. The study also indicated that there are two significant factors for success when using Blackboard in higher education teaching; knowledge of the challenges and obstacles that limit its use, and the importance of faculty member training [10] .

to understand the trends of public university faculty members in the United States of America, in terms of using Blackboard through the database available in the Educause Center for Analysis and Research in the period between 2008 and 2016. study showed that most faculty members use the features available in the Blackboard effectively, such as announcements, electronic educational content, grades, and file uploads. The results indicated that the faculty's use of Blackboard features in the period 2008 to 2016 has changed positively [11].

In another study conducted to determine the trends of faculty members at the University of Ha'il toward using Blackboard, The researcher used the descriptive analytical method. The results of this study concluded that faculty members have positive attitudes toward using the Blackboard, although it is not sufficiently utilized, and that there is a need to provide faculty training on using Blackaord. It also showed no statistically significant differences among faculty members in their attitudes toward using the Blackboard based on the variables of gender and colleges [12].

Another study aimed at identifying the effectiveness of participatory e-learning based on the use of the Blackboard in developing e-design skills and learning impact among students of the Faculty of Computing at the Islamic University of Madinah. The researcher used the experimental method, and the results showed that there is a significant impact from the application of the Blackboard system on increasing achievement in both cognitive and technical skills of students, as well as increasing their motivational achievements [2].

In the College of Computers and Information at Imam Muhammad bin Saud University, a study was conducted to reveal the trends of faculty members and students towards their use of the blackboard system in learning, the results indicated a positive trend in the use of the blackboard system by faculty members and students of the College of Computers and Information [13]. Moreover a study aimed at identifying the impact of a proposed training program to impart faculty members at the University of Ha'il with the skills needed to build electronic tests using the Blackboard system. The study found that there are statistically significant differences on the achievement test of scientific knowledge in building electronic tests using the Blackboard system and there are statistically significant differences on the practical performance note of building electronic tests skills using the Blackboard system, due to the proposed training program [14].

a study aimed at identifying the trends of faculty members toward using the Blackboard system, as well as most important challenges that hinder Blackboard system use. The researchers used a questionnaire to collect the necessary data on a sample of (195) faculty members. The study found some important results: faculty members' trends toward using the Blackboard system are moderately positive, and there are statistically significant differences in favor of females, training, and teaching experience. [15] Furthermore, A study aimed to 
determine the reality of using the Blackboard by students and faculty members in the Department of Educational Technology at King Saud University. The study used the descriptive method, and the study sample was intentional, consisting of female students studying in the Department of Educational Technology. There were no significant differences due to the academic grade and training courses variables [16].

A study aimed at indicating the trends of faculty members in Saudi universities toward using the Jusur e-learning management system. The results revealed that there are positive trends in the study sample toward using the Jusur system, although it was not effectively utilized, and that there is an urgent need for training on how to use the Jusur system and its features. Additionally, there are no statistically significant differences in trends toward using the system for the variable of faculties (Humanitarian, Science, and Medical) [17]. A study aimed at identifying student and faculty trends toward the use of Blackboard at The University of Queensland in Australia. The researchers used quantitative and qualitative methods to identify the opinions of students and faculty members on using Blackboard. The results indicated that Blackboard from the perspective of students and faculty members is characterized by an effective learning environment, and that the Blackboard system enhances the educational process. Furthermore, faculty members pointed out that using the Blackboard system takes more of their time, as they must prepare educational content and then upload it to the system [18].

Previous studies have helped the researcher in forming a comprehensive perception of learning management systems in general, and the Blackboard system in particular, as well as its impact on education in terms of solving educational problems and improving educational outputs. They also helped in theoretical identification of the components and features of the Blackboard system, and in identifying the most important methodological characteristics and approaches needed to study this topic and prepare the instrument as required. However, the present study focuses on the degree of use of the Blackboard system in a specific category; faculty members in the preparatory year at the University of Ha'il, as the use of the Blackboard software is mandatory in the curricula, especially in computer science, physics, chemistry and biology.

Thus, this study differs from the studies which were conducted at the University of Ha'il (14), (10). While the first study focused on building tests using Blackboard, the second fo-cused on the trends and constraints of using Blackboard. This study also includes variables not addressed in previous studies, such as the teaching language and the courses taught by the faculty members. Additionally, this study is one of the few studies at the local level to the best of the researcher's knowledge dealing with the Blackboard, as the researcher did not find any previous local studies addressing the preparatory year.

Researchers discussed the benefits and advantages of the Blackboard, which significantly contributes to the development of the educational process, provides a virtual environment that simulates the traditional teaching and training environment, and facilitates effective faculty-student and student-student communication in order to create a suitable environment for online learning. Several studies confirm that Blackboard's benefits and features have contributed effectively to e-learning [19];[20];[12];[2] and can be summarized as follows:

1. The Blackboard system enables students and faculty members to interact with the educational content, whether printed, audible or visual, at any time and place, provided that an internet connection is available.

2. The Blackboard system enables the storage of educational content in multiple electronic formats that help faculty members provide what students need in an interesting manner, and make it available to them as a course reference.

3. Blackboard system enables users to provide a virtual environment to answer queries made by students, whether through discussions, email, etc.

4. The Blackboard system enables students to enrich the discussion of course topics, allowing them to scrutinize and critique information in a virtual environment that greatly assists in developing the students' skills.

5. As mentioned above, there are several characteristics that contribute to effective communication between faculty members and students to enhance the teaching and learning process through announcements, email, discussions and chat.

6. The Blackboard system offers the opportunity to follow the educational development of students by providing students with test results (periodic or final) and the assignments required for the completion of the course - in addition to providing statistical reports on the activity and participation of students in the use of Blackboard system features.

The Government of the Kingdom of Saudi Arabia was keen to benefit from the technological revolution and sought to employ communication and information technologies within the educational process. Consequently, the Saudi e-University was established in $1432 \mathrm{AH}$ as a governmental educational institution under the supervision of the Ministry of Education to complement the work of other Saudi universities, offering several undergraduate or graduate academic programs in various disciplines in addition to offering several training courses in continuous learning and lifelong learning (https://seu.edu.sa/ar/home/). Four conferences were held in Saudi Arabia, during which experts and specialists in elearning and learning management systems. These conferences were held to further the benefits of international, Arab, and Saudi expertise, provide several sessions on scientific papers on utilizing electronic learning, and offer expertise to decisionmakers in Saudi universities. That enabled universities to benefit from international experiences in employing educational technology and achieving educational outcomes according to international quality requirements. Following the announcement of Saudi Vision 2030, the National Center for e-Learning was established, which aims to control the quality of e-learning and the tools used in the educational process. Consequently, the Saudi e-University was keen to sign an agreement with Blackboard to offer this system to Saudi 
universities in order to contribute to building an economy and community of knowledge, which will, in turn, provide quality education according to development requirements and labor market needs.

\section{DESIGN OF THE RGL SCHEME}

The University of Ha'il has implemented several projects related to the adoption of communications and information technology in its programs and courses and is being geared toward e-learning, and the use of software to help manage the process of education, such as the Blackboard software, as a new experience that did not exceed four years. The university also held training courses for faculty members on the Blackboard, and created a guide for faculty members and another for students to help them best use the system. The researcher found that some faculty members did not fully utilize the Blackboard and limited its use to assigning short tasks and tests. They did not utilize the wide range of features in the system; therefore, pursuing the present study is an important measure to identify how beneficial these projects are to the learning process of university students and their preparation for the future Additionally, identifying the level of utilization of these programs by faculty members may give us an indication of their usefulness or lack thereof, thus helping the university administration make decisions concerning them. Accordingly, the study identifies the degree of Blackboard use at the University of Ha'il from the point of view of faculty members in the Deanship of the Preparatory Year by answering the following questions:

1) What is the extent of the use of the Learning Management System (Blackboard) at the University of Ha'il by faculty members?

2) Does the use of Blackboard vary according to the background of the faculty members, such as gender, academic ranking, or number of training courses?

\section{Study objectives:}

The present study seeks to achieve the following objectives:

1. Examine faculty views toward using the Blackboard learning management system.

2. Identify the impact of study variables (gender, academic ranking, and number of Training courses) on the responses of the study sample of faculty members toward the use of the Blackboard e-learning management system in university education.

3. Provide a visualization of how to develop the knowledge of faculty members at the University of Ha'il on the use of Blackboard, according to the results of the study.

\section{PERFORMANCE EVALUATION}

The study draws its significance from the following:

1.Preparing and developing faculty members for using technology in their university practices.

2. Providing important information to decision-makers at the University of Ha'il about the extent of the Blackboard learning system's use by faculty members.

3. Identifying some aspects and points of interest that are influential in the use of the Blackboard learning system.

4. Contributing to the development of the faculty members' performance using Blackboard by identifying their training needs.

\section{STUDY TERMINOLOGY}

THIS STUDY INCLUDES A NUMBER OF TERMS:

Blackboard System the Blackboard system is "software packages that allow the faculty member to upload their course material to a website, and offer the student the opportunity to continue the learning process, as it enables students to communicate and interact with each other and communicate with the faculty member to do collaborative work in new and fun ways. It also helps educational institutions in transforming the internet into a strong and effective medium for managing the educational process." [19].

\section{Study population}

The study population consisted of (334) faculty members in the preparatory year at the University of Ha'il.

\section{Study sample}

The study sample was chosen randomly from the faculty members through the electronic distribution of the questionnaire to the faculty members. Table (1) shows the study sample and its variables by (123) members of the study population.

Table1. Demographic characteristics of participants.

\begin{tabular}{|c|c|c|}
\hline Variables & $\mathbf{N}$ & Percent \\
\hline \multicolumn{3}{|c|}{ Academic Ranking } \\
\hline Professor & 4 & 33 \\
\hline Associate Prof & 5 & 4.1 \\
\hline Assistant Prof & 35 & 28.5 \\
\hline Instructor & 79 & 64.2 \\
\hline \multicolumn{3}{|c|}{ Number of training course } \\
\hline None & 15 & 12.2 \\
\hline One course & 59 & 48.0 \\
\hline Two courses & 28 & 22.8 \\
\hline Three or more & 21 & 17.1 \\
\hline \multicolumn{3}{|c|}{ Gender } \\
\hline Male & 62 & 50.4 \\
\hline Female & 61 & 49.6 \\
\hline
\end{tabular}

Academic ranking:

Table (1) shows the academic ranking of the respondents, where $64.2 \%$ of the respondents were (Instructor), 28.5\% (Assistant Prof.), 4.1\% (Associate Prof.), and 3.3\% (Professor).

\section{Number of training courses:}

Table (1) shows the number of training courses of the respondents, where $48.0 \%$ of the respondents had (One course), $22.8 \%$ (Two courses), 17.1\% (Three or more), and 
$12.2 \%$ (None).

\section{Gender:}

Table (1) shows the gender of the respondents, where $50.4 \%$ of the respondents were male and $49.6 \%$ were female.

Study instrument

For the purposes of the study, a special questionnaire was used to measure the extent of using the Blackboard in the
University of Ha'il, from the point of view of faculty members. Data relevant to this study was collected through a review of previous literature and pre-viously adopted metrics, such as [16];[19].

Study Instrument Validity

Internal consistency is calculated by finding the correlation coefficient between each item and the total score of the scale.

Table 2. Pearson correlation coefficient

\begin{tabular}{|l|c|c|c|c|c|}
\hline & Pearson Correlation & Item & $\begin{array}{l}\text { Pearson } \\
\text { Correlation }\end{array}$ & Item & Pearson Correlation \\
\hline 1 & $.731^{* *}$ & 11 & $.837^{* *}$ & 21 & $.738^{* *}$ \\
\hline 2 & $.691^{* *}$ & 12 & $.847^{* *}$ & 22 & $.830^{* *}$ \\
\hline 3 & $.744^{* *}$ & 13 & $.885^{* *}$ & 23 & $.850^{* *}$ \\
\hline 4 & $.457^{*}$ & 14 & $.712^{* *}$ & 24 & $.803^{* *}$ \\
\hline 5 & $.840^{* *}$ & 15 & $.809^{* *}$ & 25 & $.956^{* *}$ \\
\hline 6 & $.856^{* *}$ & 16 & $.835^{* *}$ & 26 & $.888^{* *}$ \\
\hline 7 & $.546^{*}$ & 17 & $.828^{* *}$ & 27 & $.853^{* *}$ \\
\hline 8 & $.863^{* *}$ & 18 & $.809^{* *}$ & 28 & $.892^{* *}$ \\
\hline 9 & $.651^{* *}$ & 19 & $.893^{* *}$ & 29 & $.834^{* *}$ \\
\hline 10 & $.674^{* *}$ & 20 & $.699^{* *}$ & 30 & $.859^{* *}$ \\
\hline 31 & $.883^{* *}$ & 32 & $.828^{* *}$ & & \\
\hline
\end{tabular}

The results of the statistical analysis of the correlation coefficient, as shown in Table (2), indicate that there is a statistically significant correlation at the level of $\mathrm{Sig}=0.05$ between the scores of each item and the total score of the scale.

\section{Study Instrument Reliability}

The researcher used the Cronbach's alpha method for calculating the stability of scale, where its value was 0.981 (Table 3), which indicates the existence of a relationship and the consistency of high correlation between the expressions of the questionnaire. Therefore, we can be confident in the credibility of the measure in achieving the objectives of the study.

Table 3. Cronbach's alpha scale.

\begin{tabular}{|c|c|}
\hline Numbers of Items & Cronbach's Alpha \\
\hline 32 & 0.981 \\
\hline
\end{tabular}

\section{Data processing and statistical analysis}

The study instrument was distributed to a sample of (123) members using SPSS software for statistical analysis; the arithmetic means, standard deviations and the t-value were calculated after collecting the faculty members' questionnaire answers. The following model shows the effectiveness of using the Blackboard at the University of Ha'il from the point of view of the faculty members, according to a Likert five-point scale, by giving each of its items one of five degrees (strongly agree, agree, neither agree nor disagree, disagree, strongly disagree), which are digitally represented as $(5,4,3,2,1)$, respectively. The following standard has been adopted for the purposes of analyzing the results in Table (4):

Table 4. Estimates of arithmetic means.

\begin{tabular}{|l|l|}
\hline Estimate & Arithmetic Mean \\
\hline Very Low & 1.00 to 1.79 \\
\hline Low & 1.8 to 2.6 \\
\hline Medium & 2.61 to 3.4 \\
\hline High & 3.41 to 4.2 \\
\hline Very High & above 4.2 \\
\hline
\end{tabular}

\section{STUDY RESULTS AND DISCUSSION}

Research question 1

To answer the first question What is the extent of faculty member use of the Learning Management System (Blackboard) at the University of Ha'il?, the mean and Standard Division and ranking were measured. The mean level of Blackboard use was ranked from the most use to the least use. As shown in Table (5), the score of answers comes in two levels (Moderate and High). Where all elements have a high use, the mean ranges between (3.99-3.46), except for the items 4 and $20(\mathrm{M}=3.36$ and 3.11, respectively). The responses of the item (Blackboard contributes to deliver the knowledge) scored $(M=3.99)$, which indicates a high use of this item. The lowest score of responses was Technical problems are seldom in Blackboard $(\mathrm{M}=3.11)$, which indicates moderate use of this item. The overall mean was $(\mathrm{M}=3.68)$, which indicates a high use of the Blackboard system.

Table 5. Means and Standard Deviations of Degree of use of Blackboard.

\begin{tabular}{|c|l|c|c|c|c|}
\hline No. & \multicolumn{1}{|c|}{ Item } & M & SD & Rank & Level \\
\hline 1 & Signing into Blackboard and using the navigation bar are easy for me. & 3.93 & 0.960 & 4 & High \\
\hline 2 & $\begin{array}{l}\text { The Blackboard workshop positively affected my teaching with } \\
\text { Blackboard. }\end{array}$ & 3.93 & 0.990 & 3 & High \\
\hline
\end{tabular}




\begin{tabular}{|c|c|c|c|c|c|}
\hline 3 & I can use Blackboard tools easily and clearly. & 3.54 & 0.977 & 26 & High \\
\hline 4 & I can design my course page on Blackboard. & 3.36 & 1.049 & 31 & Moderate \\
\hline 5 & I enjoy using the interaction features on Blackboard. & 3.63 & 1.026 & 21 & High \\
\hline 6 & I can access Blackboard easily from my home or university campus. & 3.85 & 1.087 & 8 & High \\
\hline 7 & Blackboard provides the instructors with information for each course. & 3.58 & 0.878 & 25 & High \\
\hline 8 & Blackboard contributes to delivering knowledge. & 3.99 & 0.936 & 1 & High \\
\hline 9 & Blackboard is considered a trusted reference source. & 3.89 & 0.847 & 5 & High \\
\hline 10 & I can reach the information on Blackboard at any time. & 3.76 & 1.027 & 11 & High \\
\hline 11 & E-books / E-materials on Blackboard are of high quality. & 3.65 & 0.975 & 19 & High \\
\hline 12 & Blackboard presents an advanced interactive interface. & 3.69 & 0.924 & 14 & High \\
\hline 13 & Blackboard has a pleasant design for the user. & 3.50 & 1.011 & 29 & High \\
\hline 14 & Blackboard is a good choice as an educational tool. & 3.59 & 0.965 & 24 & High \\
\hline 15 & Blackboard provides a quick service for learning. & 3.54 & 1.018 & 27 & High \\
\hline 16 & Blackboard encourages self-learning. & 3.81 & 0.926 & 10 & High \\
\hline 17 & The number of steps to submit an assignment is acceptable. & 3.46 & 0.977 & 30 & High \\
\hline 18 & The steps to accomplish an assignment are in a logical sequence. & 3.62 & 0.864 & 22 & High \\
\hline 19 & The order of the information is well organized. & 3.54 & 0.977 & 28 & High \\
\hline 20 & Technical problems are rare in Blackboard. & 3.11 & 1.026 & 32 & Moderate \\
\hline 21 & $\begin{array}{l}\text { Blackboard has a variety of learning tools (email, discussion forum, } \\
\text { chat, quizzes, etc.). }\end{array}$ & 3.60 & 0.947 & 23 & High \\
\hline 22 & Blackboard has fast order processing. & 3.72 & 0.843 & 12 & High \\
\hline 23 & My experience using Blackboard was better than I expected. & 3.64 & 0.933 & 20 & High \\
\hline 24 & Using Blackboard is essential to increase students' achievements. & 3.66 & 0.990 & 18 & High \\
\hline 25 & I am satisfied with using Blackboard. & 3.67 & 0.989 & 16 & High \\
\hline 26 & I am satisfied with my experience in using Blackboard. & 3.70 & 0.932 & 13 & High \\
\hline 27 & Using Blackboard in my teaching was a good decision. & 3.86 & 0.969 & 7 & High \\
\hline 28 & I will use Blackboard in my teaching in the future. & 3.82 & 1.000 & 9 & High \\
\hline 29 & I will use Blackboard continuously. & 3.67 & 0.964 & 17 & High \\
\hline 30 & I encourage my colleagues to use Blackboard in their teaching. & 3.88 & 0.980 & 6 & High \\
\hline 31 & $\begin{array}{l}\text { Using Blackboard will increase interaction among students and faculty } \\
\text { members. }\end{array}$ & 3.98 & 0.958 & 2 & High \\
\hline 32 & $\begin{array}{l}\text { Using Blackboard will contribute to the improvement of the students' } \\
\text { outcomes. }\end{array}$ & 3.67 & 1.052 & 15 & High \\
\hline & Overall & 3.68 & 0.696 & & High \\
\hline
\end{tabular}

This result is consistent with the studies [12];[13] and[18] , which indicated positive and effective trends toward using Blackboard by faculty members. However, it differed from the study of both studies [20];[21], which indicated that faculty members' use of the Blackboard learning system was only at a "Medium" degree. The "High" degree of Blackboard use by faculty members in the preparatory year may be due to the prevalence of e-learning culture, as a result of the novelty of this type of learning for them and their familiarity with the competencies required to utilize learning management systems to the fullest, especially as the University of Ha'il is moving toward using the Blackboard learning management system in all its faculties. Teaching using a supportive style is compulsory in all courses at the direction of the university, meaning that the training unit at the Deanship of the Preparatory Year provides continuous support to all its staff, especially new members. Additionally, the interaction that occurs between faculty members, the exchange of experiences, and the availability of computer labs and learning resource centres, would raise a level of enthusiasm and competition among faculty members in dealing with the Blackboard.

\section{A. Research question 2}

Regarding the second question "Does the use of Blackboard vary based on faculty member background, such as gender, academic ranking, or number of training courses?", There are no statistically significant differences in the use of Blackboard based on faculty member background, such as gender, academic ranking, or number of training courses. A KruskalWalis test was used to determine whether there were significant differences in the use of Blackboard based on faculty member background. Mann-Whitney test was used to determine whether there were significant differences in the use of Blackboard based on the faculty's gender. 
Table 6. Kruskal-Walis \& Mann-Whitney for statistically significant differences on the means of the use of Blackboard according to demographic characteristics.

\begin{tabular}{|c|c|c|c|}
\hline Variables & Mean (SD) & Mean Ranking & Test Statistic (P) \\
\hline \multirow{4}{*}{$\begin{array}{l}\text { Academic Ranking } \\
\text { Professor } \\
\text { Associate Prof. } \\
\text { Assistant Prof. } \\
\text { Instructor }\end{array}$} & $3.74(0.759)$ & 65.2 & \multirow{4}{*}{$\mathrm{K}=3.008(0.390)$} \\
\hline & $3.57(0.572)$ & 54.9 & \\
\hline & $3.85(0.278)$ & 72.3 & \\
\hline & $3.43(0.752)$ & 48.5 & \\
\hline \multirow{4}{*}{$\begin{array}{l}\text { Number of training } \\
\text { courses } \\
\text { None } \\
\text { One course } \\
\text { Two courses } \\
\text { Three or more }\end{array}$} & $3.81(0.762)$ & 69.7 & \multirow{4}{*}{$\mathrm{K}=4.441(0.218)$} \\
\hline & $3.57(0.728)$ & 57.1 & \\
\hline & $3.67(0.591)$ & 59.1 & \\
\hline & $3.93(0.654)$ & 74.1 & \\
\hline \multirow{2}{*}{$\begin{array}{l}\text { Gender } \\
\text { Male } \\
\text { Female }\end{array}$} & $3.70(0.716)$ & 63.0 & \multirow{2}{*}{$\mathrm{U}=1828.0(0.750)$} \\
\hline & $3.66(0.680)$ & 60.9 & \\
\hline
\end{tabular}

$\mathrm{K}=$ Kruskal-Walis, $\mathrm{U}=$ Mann-Whitney, $\mathrm{SD}=$ Standard Deviation and $\mathrm{P}=\mathrm{P}$-value.

\section{Academic Ranking}

The Kruskal-Walis test revealed that there were no statistically significant differences $(\mathrm{p}=0.390)$ in the use of Blackboard based on academic ranking: professor $(\mathrm{M}=3.74)$, Associate Prof. $(\mathrm{M}=3.57)$, Assistant Prof. $(\mathrm{M}=3.85)$ and instructor ( $\mathrm{M}$ $=3.43$ ). Academic ranking did not appear to make a significant difference in the use of Blackboard (see Table 6). Their responses did not differ according to the academic rank as they deal with databases, the digital library, search engines, educational sites, the multimedia provided by the Internet and the richness of knowledge in addition to making use of electronic services. This led to a growing awareness of the importance of e-learning and electronic teaching strategies, where trends are formed through emotional experiences. When the emotional experience that an individual goes through in a particular situation is good, his direction is positive and vice versa regardless of the academic rank. These findings were consistent with previous studies. The result of this study is similar to [22], which showed that there were no differences between faculty members' perception and their academic ranking. Moreover, a study examined faculty members' perception at Northern Border University toward the use of the Blackboard based on academic ranking [23]. The result showed that there was no statistically significant difference between the academic ranking of faculty members and their use of Blackboard in their teaching. The results of the present study are in agreement with the results of in their results indicated that there were no statistically significant differences between faculty members and their academic ranking, [16]. However, one study did apply an investigation comparison with faculty members at King Saud University and KSU based on academic ranking. It showed that the lecturer and assistant professor was likely to use Blackboard in teaching due to the ability of the lecturer and assistant professor to use technology, thanks to their competent technology skills [24].

Number of training courses

As shown in Table (6), The Kruskal-Walis test results revealed that there were no statistically significant differences $(p=0.218)$ in the use of Blackboard based on the number of

Training courses: None $(\mathrm{M}=3.81)$, One course $(\mathrm{M}=3.57)$, Two courses $(M=3.67)$ and Three or more $(M=3.93)$. Number of training courses did not appear to make a significant difference in the use of Blackboard. The researchers attributes this result to the spread of the culture of e-learning and distance education in various media and academic forums. The result of this study is consistent with the results which found that there were no statically significant differences between faculty members in using Blackboard based on academic ranking [23];[20];[16];[10]. On the other hand, a study found the training courses positively affected faculty members' perception in using blackboard in their teaching [10]. Similarly,the training courses increased the use of blackboard in the faculty courses [25];[15].

\section{Gender}

The Mann-Whitney test results revealed that there were no statistically significant differences $(\mathrm{p}=0.846)$ in the use of Blackboard based on gender: Male $(M=3.70)$ and Female ( $M$ =3.66). Gender did not appear to make a significant difference in the use of Blackboard (Table 6). The researchers attribute this result to the awareness of faculty members of both sexes of the importance of using the blackboard and that it may help in achieving the goals of the educational process, given that most of them engage in the same academic tasks, in addition to the similarity in the cultural and social environment in which they work in general and their acquisition of skills and technological expertise. The literature presented several studies that examined faculty members' use of Blackboard based on gender [24];[25];[26];[27].The result of this study showed that there were no statistically significant differences in the use of Blackboard based on gender. The studies reached the same result as the current study [23]; [28]. On the contrary, female faculty members showed greater use of the blackboard as [21.Another study found that male faculty members used blackboard more in their courses than female teachers [25]; [29]. 


\section{Study conclusion and recommendations}

This research was conducted at University of Ha'il, where it is encouraging their faculty members to use Blackboard in their teaching. The result of the study showed that the faculty members recorded high rating in using Blackboard at Deanship of Preparatory Year at University of Ha'il. Moreover, this study measured whether there were statistically significant differences in using Blackboard among some variables such as gender, academic ranking, or number of training courses of faculty members' background. The results reported that there were no statistically significant differences between the faculty members and their gender. This revealed that both gender males and females have a good knowledge of technology use. Additionally, the findings of this study indicated that there were no statically differences between faculty members and their academic ranking and the numbers of training courses in using Blackboard. So, most of the participants were young instructors and this is considered as an indicator to utilizing Blackboard effectively in their teaching. Given the results of this study, the researcher recommends more information for the faculty members of the successful experiences of colleagues using the Blackboard is necessary. It helps the university faculty apply Blackboard features in distance teaching. In addition, future research is needed to examine the effect of different variables on faculty members' use of Blackboard.

A qualitative research study is needed to gain a clear insight into the faculty and student experiences with Blackboard in courses. These studies are necessary to explore how well faculty members use Blackboard in their courses from a student's perspective. This will give the faculty members and the university administration a clear vision for the effective use of Blackboard in teaching, as the evaluation of usage practices from the students' point of view is of utmost importance as they are the central aspect by identifying the negative and positive aspects in the performance of the Faculty Members to develop his teaching performance on the other hand. Examining students 'views of faculty members' use of technology in future research. Comparative studies can be applied to find relationships between faculty and student opinions about the use of Blackboard in distance learning

\section{CONCLUSIONS}

The limitation of the study is that it was only conducted on the faculty members of the Deanship of Preparatory Year at the University of Ha'il. The current study was applied in the first semester of the academic year (2017 - 2018). Other limitations appeared in the missing of the students' views of the faculty use of technology in Blackboard courses. The study data depends on self-rating research instruments applied by the faculty members. Therefore, this leads to the lack of differences between the faculty' views and the students' views.

Funding: The search (No. BA-1516) funded by Scientific Research at the UOH, Hail, KSA. The funding source had no involvement in any aspect of the study design, delivery or publication.

\section{References}

[1] Shaqour, A., \& Al Saadi, R. (2015). The Degree of Readiness of An-Najah National University Teachers in Using Moodle in the Teaching Process According to Technological Pedagogical Content Knowledge Framework. An-Najah University Journal for Research, 29(8), 1489- 1518.

[2] AbdulWahab, M. (2016). The Effectiveness of Participatory E-learning Based on the Use of Blackboard E-learning Management System in Developing E-design Skills and the Survival of Learning Imapct among Students of the Faculty of Computing at the Islamic University of Madinah, Educational Journal, Egypt (46). pp. 326-301. https://doi.org/10.12816/0037894

[3] Nazli Goker, Mehtap Dursun, Elif Dogu, A Cognitive Mapping Approach for Evaluation of Success Indicators of IT Transformation Project, Engineering World, pp. 9699, Volume 2, 2020

[4] Roumen Trifonov, Georgi Tsochev, Ognian Nakov, Galya Pavlova, Slavcho Manolov, Possibilities for Improving the Quality of Cyber Security Education through Application of Artificial Intelligence Methods, Engineering World, pp. 145-149, Volume 2, 2020

[5] Jacek, U, Oladiran, T, Edmund, L., and Kurt, B. (2016). Students' and Instructor's Perspective on the use of Blackboard Platform for Delivering an Engineering Course. The Electronic Journal of e-Learning Volume 16(1), pp 1-15, available online at www.ejel.org

[6] Zaki, H. A. and El Zawaidy, H., 2014. Using Blackboard in online learning at Saudi universities: Faculty member's perceptions and existing obstacles. The International Journal of Interdisciplinary Educational Studies, 3(7), pp.141-150.

[7] Al-Naibi, S., Madarsha, K. (2015). Blackboard Use by Faculty Members in the Colleges of Applied Sciences in the Sultanate of Oman. International Journal for Innovation Education and Research, 3 (4), 26-40.

[8] Little-Wiles, J., \& Naimi,L. L. (2018). Faculty Perceptions of and Experiences in Using the Blackboard Learning Management System. Feature Edition, 2018(4), 13-25.

[9] Al-Manhrawi, D. M. (2015). The reality of using the Learning Management System (Blackboard) by faculty members in the College of Education in light of the availability of e-learning competencies: reality and expectations. Journal of Education Technology - Studies and Research, (25), 91-126.

[10] Shipman, C. D. (2017). Perceptions of Faculty toward Integrating Technology in Undergraduate Higher Education Traditional Classrooms at Research-Focused Regional Universities in South Texas (Doctoral dissertation, Texas A\&M University-Kingsville).

[11] Rhode, J., Richter, S., Gowen, P., Miller, T., \& Wills, C. (2017). Understanding Faculty Use of the Learning Management System. Online Learning, 21(3), 68-86. https://doi.org/10.24059/olj.v21i3.1217

[12] AlBalassi, R. (2016). Trends of Faculty Members in the University of Ha'il towards Using the Blackboard 
Learning Management System. Journal of Arabic Studies in Education and Psychology, (69), 103-120. https://doi.org/10.12816/0022654

[13] AbdulWahab, M. (2016). The Effectiveness of Participatory E-learning Based on the Use of Blackboard E-learning Management System in Developing E-design Skills and the Survival of Learning Imapct among Students of the Faculty of Computing at the Islamic University of Madinah, Educational Journal, Egypt (46). pp. 326-301. https://doi.org/10.12816/0037894

[14] Al-Sadhan, A. (2015). Trends of Students and Faculty Members of the Faculty of Computer and Information Sciences in Imam Muhammad ibn Saud Islamic University Towards Using the Blackboard E-learning Management System and Its Relation to Some Variables, Journal of Educational Sciences, 2 pp. 278-222. https://doi.org/10.12816/0015677

[15] Shoaib, I. (2014). The Impact of Proposed Training Program to Help the Faculty Staff Members at the University of Ha'il Acquire the Skills of Preparing Electronic Tests of Management System Learning Blackboard: Journal of Arabic Studies in Education and Psychology, 53. https://doi.org/10.12816/0022491

179-201.

[16] Mazrou, Y. (2013). Trends of Faculty Members at King Khalid University Towards the Use of the Blackboard Elearning Management System. Journal of the Educational Society for Social Studies - Egypt (52) pp $114-84$.

[17] AlAmro, R. (2012). The Reality of Using the Blackboard Learning Management System by Students and Faculty Members in the Department of Educational Technology. Unpublished Master Thesis, College of Education, King Saud University.

[18] Hussein, H. (2011). Trends of Faculty Members in Saudi Universities Towards Using the Jusur E-learning Management System. Turkish Online Journal of Educational Technology, 10 (2) pp. 43-53.

[19] Heirdsfield, A., Walker, S,. Tambyah, M,. \& Beutel, D. (2011). Blackboard as an Online Learning Environment: What Do Teacher Education Students and Staff Think?. Australian Journal of Teacher Education, 36(7), 1-17. https://doi.org/10.14221/ajte.2011v36n7.4

[20] AlJarrah, A. (2011). Trends of Jordanian University Students Towards Using the Blackboard Software in Their Learning. Journal of Jordanian University Studies, 3 (4), pp. 1293-1304.

[21] Sayaf, A., \& AlQahtani, M. (2014). Evaluation of the Experience of King Khalid University in the Use of Blackboard E-learning Management System: Educational Technology. Journal of Studies and Research - Egypt, pp. 59-71.

[22] Mohammed, M. (2015). The Development of E-learning Management in Egyptian Universities in the Light of the Blackboard System, Journal of Psychological and Educational Research - Faculty of Education Menoufia University - Egypt (30) 4 p41-96.

[23] Ibrahim, L. K., Mohamed, A. G., Aldhafeeri, F. M., \& Alqdah, M. (2019). Faculty members' perceptions towards utilizing blackboard in teaching system at Hafr Al-Batin University, Saudi Arabia. Journal of Nursing Education and Practice, 9(5). https://doi.org/10.5430/jnep.v9n5p64.

[24] Ibrahem, U. M., \& Alamro, A. R. (2021). Effects of Infographics on Developing Computer Knowledge, Skills and Achievement Motivation among Hail University Students. International Journal of Instruction, 14(1).

[25] Ibrahem, U. M., Alamr, A. R. (2020). The Effect of Using Cinemagraph Pictures in Social Platforms and Mobile Applications in the Development of Peace Concepts among University of Hail Students, JOURNAL OF INFORMATION SCIENCE AND ENGINEERING, 37(6), (November 2021).

[26] Rabeh, M. D. (2019). E-learning Management System by Blackboard: A Survey of the Trends of Faculty Members at the University Level. IJCSNS, 19(5), 210. Doi: 10.13140/RG.2.2.18483.37921.

[27] Alshalan, T. (2019). The adoption of learning management systems (LMS) among faculty members at Kansas State University and King Saud University (Doctoral dissertation).

[28] Almeajel, T, M \& Sharadgah, T, A. (2018). Barriers to using Blackboard system in Teaching and Learning: Faculty perceptions. Tech Know Learn. 23(2), 351-366.

[29] Ibrahem, U M., Alaraby H.Y., \& Diab H. M. (2020).Interaction between Feedback Types of Interactive Videos Used in Flipped Classroom and Learning Styles of Talented Students in Developing Personal Knowledge Management Skills and Achievement, INTERNATIONAL JOURNAL OF EDUCATION AND INFORMATION TECHNOLOGIES, Vol 14. 182-204, http://doi.org/10.46300/9109.2020.14.21.

\section{Creative Commons Attribution License 4.0 (Attribution 4.0 International, CC BY 4.0)}

This article is published under the terms of the Creative Commons Attribution License 4.0 https://creativecommons.org/licenses/by/4.0/deed.en US 